\title{
Climate signals are reflected in an 89 year series of British Lepidoptera records
}

\author{
Roger L. H. DENNIS ${ }^{1,2}$ and Tim H. SPARKS ${ }^{1 *}$ \\ ${ }^{1}$ NERC Centre for Ecology and Hydrology, Monks Wood, Abbots Ripton, Huntingdon, Cambridgeshire PE28 2LS, UK \\ ${ }^{2}$ Institute for Environment, Sustainability and Regeneration, Room s122, Mellor Building, Staffordshire University, College Road, \\ Stoke on Trent, ST4 2DE, UK
}

Key words. Lepidoptera, historical records, population changes, climate change, migration

\begin{abstract}
Historical data sources on abundance of organisms are valuable for determining responses of those organisms to climate change and coincidence of changes amongst different organisms. We investigate data on the general abundance of Lepidoptera over an 89 year period $1864-1952$. We related abundance to monthly mean temperature and precipitation and the winter North Atlantic Oscillation (NAO) index, and to numbers of migrants from an independent source. Abundances of Lepidoptera were significantly positively correlated with current year temperatures for May to September and November and significantly negatively correlated with temperatures in January. Numbers were also negatively correlated with rainfall for April and May and annual total of the current year and with August in the previous year. Abundance of Lepidoptera decreased significantly with an increasing winter NAO index. Increased overall abundance in Lepidoptera coincided significantly with increased numbers of migrants. The climate associations were very similar to those previously reported for butterfly data collected by the British Butterfly Monitoring Scheme; although warm and drier summers were generally beneficial to Lepidoptera populations, wet summers and winters and mild winters were not. We discuss the implications for Lepidoptera biology and populations in regions of Britain in the face of projected climate changes.
\end{abstract}

\section{INTRODUCTION}

Historical data sources on the abundance of organisms are potentially valuable for determining the relationship between biological responses and climate changes (Sparks et al., 2005, 2006), though are rare, even for recent decades (Dell et al., 2005). Expectations of such datasets are twofold. Firstly, despite the independent effects of other factors (predators, parasites, disease) on abundances the data should provide clear signals of climate influences, particularly as weather and climate agents also operate on more direct factors such as numbers of enemies (Dennis, 1993). There may be well recognised delays in any population response to climate changes and fluctuations but these should still be evident (Pollard, 1988). Secondly, although responses to climate by different organisms will vary in relation to their habitats (resource use), habits and life histories, there should be significant correlations among different data sets of the same taxon for the same periods in the same region, for instance between resident and migrant Lepidoptera species subject to the same broad climatic influences. Evidence for significant associations between historical data sets of animal abundances and climate agents and among abundance datasets for different groups of organisms over long time periods provides an important context for understanding the impact of projected climatic changes (Leather et al., 1994; Hill et al., 2002).

Clear expectations between abundances of Lepidoptera and weather and climate have emerged from relationships established for monitored populations over relatively short time periods using quantitative synoptic survey, particularly the British Butterfly Monitoring Scheme (BMS, Pollard \& Yates, 1993). Pollard (1988) investigated changes in BMS abundances for 31 butterfly species for the period 1976 to 1986 and found the most striking associations to be between (i) increased numbers and warm dry summers and (ii) wet conditions early in the previous year and increased numbers in the current year. However, winter temperature and rainfall showed no strong associations with numbers of butterflies. These data were reinvestigated for the period 1976 to 1997 by Roy et al. (2001). They found strong associations between weather and population fluctuations and trends in 28 of 31 species which confirmed Pollard's (1988) findings.

What has not been investigated until now is the association between the overall abundance of Lepidoptera and climate for a longer historical period. Here, we investigate data for the general abundance of all Lepidoptera in Britain for an 89 year period straddling the last two centuries (1864 to 1952) (Beirne, 1955). In the process of studying the origins and history of British Lepidoptera, Beirne examined several thousand papers in entomological journals describing annual abundances of moths and butterflies. These fluctuations in overall abundance of Lepidoptera he summarised using brief verbal descriptions. This is unlike historical data previously examined; data from the county of Wiltshire, UK explored by Sparks et al. (2006) where many resident species $(\mathrm{n}=155)$ were considered for a relatively short period of years $(n=19)$ in the $19^{\text {th }}$ century, or the long set of annual data for 29

\footnotetext{
* Corresponding author; e-mail: ths@ceh.ac.uk
} 
TABLE 1. Coding applied to B.P. Beirne's (1955) descriptions applied to Lepidoptera abundances.

\begin{tabular}{lc}
\hline \multicolumn{1}{c}{ Descriptions $^{1}$} & Coding \\
\hline Very good year & 4 \\
Good year & 3 \\
Good year but with negative features & 2 \\
Above average year & 1 \\
Average year & 0 \\
Below average year & -1 \\
Bad year but with positive features & -2 \\
Bad year & -3 \\
Very bad year (not applied) & -4 \\
\hline
\end{tabular}

${ }^{1}$ Descriptions are statements taken verbatim from Beirne (1955). Codes 2 and -2 are years described as good and bad respectively but qualified to be somewhat worse or better than good or bad.

non resident, long-distance, migrant species to the UK from 1850 to 1962 (Williams, 1965).

Two hypotheses are investigated. Firstly, that overall abundance of, predominantly resident, Lepidoptera will correlate with overall abundance for migrants into the British Isles. Climate triggers differ in location, migration being generated by conditions at the continental places of origin (i.e., France, Spain) and numbers of residents by conditions in Britain. Nevertheless conditions are expected to coincide to some extent among neighbouring regions; bad years for residents are unlikely to generate good conditions for migrants whereas good years for residents are likely to be associated with conditions conducive to immigration and establishment of temporary populations of migrants. The overall abundance data from Beirne are compared directly with numbers of Lepidoptera migrants into Britain observed for the equivalent period (Williams, 1965). Secondly, abundances described by Beirne are influenced by monthly and annual mean temperature and precipitation for the relevant current and previous year, and with the North Atlantic Oscillation (NAO) winter index (the latter a surrogate for rainfall and cloud). From findings generated by the British BMS, it is expected that abundances will increase with temperatures and decrease with the strength of the NAO.

\section{MATERIAL AND METHODS}

Descriptions of overall UK Lepidoptera abundance (butterflies and moths) from 1864 to 1952 (Beirne, 1955: 25-26) have been converted to a 9 point scale ( -4 very bad, through 0 average, to +4 very good; Table 1$)$. Log transformed numbers of 29 migrant butterfly and moth species into the British Isles for the same period have been extracted from Williams (1965) and averaged across species. It is not known to what extent the data sources of these two authors overlapped, but we believe, given the dominance of resident species among British Lepidoptera, that the overlap is small.

The temperature data used here are the monthly means from the Central England Temperature (CET) series (Parker et al., 1992), regularly updated by the Hadley Centre and available on the UK Met Office website (www.met-office.gov.uk/research/ hadleycentre/obsdata/cet.html). Monthly rainfall data used are the England and Wales Precipitation (EWP) series (Wigley et
TABLE 2. Correlations (above) and randomisation p values (below) comparing the Beirne abundance data to mean monthly and annual Central England Temperatures (CET) and England and Wales Precipitation (EWP) of the current and previous year. Figures in bold are significant at $p<0.05$.

\begin{tabular}{|c|c|c|c|c|}
\hline & \multicolumn{2}{|c|}{ Correlations with CET } & \multicolumn{2}{|c|}{ Correlation with EWP } \\
\hline & current & previous & current & previous \\
\hline \multirow[t]{2}{*}{ Jan } & -0.276 & -0.018 & -0.123 & -0.081 \\
\hline & 0.012 & 0.874 & 0.224 & 0.469 \\
\hline \multirow[t]{2}{*}{ Feb } & -0.174 & -0.007 & -0.034 & -0.131 \\
\hline & 0.104 & 0.948 & 0.756 & 0.235 \\
\hline \multirow[t]{2}{*}{ Mar } & -0.118 & -0.045 & 0.069 & -0.077 \\
\hline & 0.282 & 0.664 & 0.511 & 0.473 \\
\hline \multirow[t]{2}{*}{ Apr } & -0.064 & 0.020 & -0.264 & 0.003 \\
\hline & 0.560 & 0.845 & 0.012 & 0.983 \\
\hline \multirow[t]{2}{*}{ May } & 0.276 & -0.048 & -0.273 & -0.012 \\
\hline & 0.006 & 0.658 & 0.010 & 0.915 \\
\hline \multirow[t]{2}{*}{ Jun } & 0.277 & -0.037 & -0.173 & -0.020 \\
\hline & $\mathbf{0 . 0 0 7}$ & 0.739 & 0.102 & 0.865 \\
\hline \multirow[t]{2}{*}{ Jul } & 0.303 & 0.042 & -0.174 & -0.086 \\
\hline & $\mathbf{0 . 0 0 7}$ & 0.724 & 0.114 & 0.429 \\
\hline \multirow[t]{2}{*}{ Aug } & 0.224 & 0.202 & -0.104 & -0.225 \\
\hline & $\mathbf{0 . 0 3 8}$ & 0.055 & 0.350 & $\mathbf{0 . 0 3 3}$ \\
\hline \multirow[t]{2}{*}{ Sep } & 0.233 & 0.191 & -0.124 & -0.097 \\
\hline & 0.024 & 0.054 & 0.256 & 0.355 \\
\hline \multirow[t]{2}{*}{ Oct } & -0.103 & -0.104 & -0.005 & 0.050 \\
\hline & 0.329 & 0.345 & 0.967 & 0.661 \\
\hline \multirow[t]{2}{*}{ Nov } & 0.233 & 0.163 & -0.025 & 0.148 \\
\hline & 0.029 & 0.133 & 0.832 & 0.173 \\
\hline \multirow[t]{2}{*}{ Dec } & 0.083 & -0.078 & 0.074 & 0.032 \\
\hline & 0.452 & 0.457 & 0.507 & 0.760 \\
\hline \multirow[t]{2}{*}{ Annual } & 0.106 & 0.039 & -0.283 & -0.134 \\
\hline & 0.319 & 0.704 & 0.008 & 0.215 \\
\hline
\end{tabular}

al., 1984), also updated by the Hadley Centre and available on the UK Met Office website (www.met-office.gov.uk/research/ hadleycentre/obsdata/HadEWP.html). NAO monthly values, normalised pressure differences across the North Atlantic (Hurrell, 1995), were obtained from the Climatic Research Unit website (www.cru.uea.ac.uk). A winter NAO index was calculated as the mean of the months from December to March when high index values result in enhanced westerly air flows (mild, damp conditions).

Associations between the overall abundance data with migrant data and with climatic data have been assessed using Pearson correlations but, because of some concerns about the distribution of the Beirne data, significance was estimated using resampling methods based on 1000 randomisations (Manly, 1991). In practice this made very little difference to the significance levels compared to the parametric method. Readers should be aware that, with a large number of correlations as here, some significant correlations may arise by chance. Multiple relationships were examined using stepwise multiple linear regression (forwards entry) following which normality of the residuals was assessed. The significance threshold is taken as $p$ $=0.05$. 


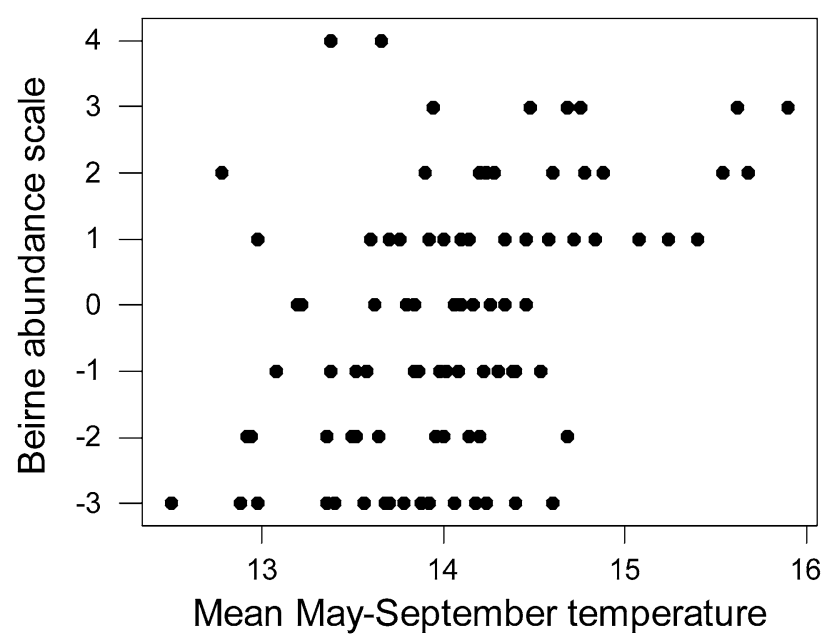

Fig. 1. The relationship between the Beirne abundance scale for British Lepidoptera and mean May-September Central England Temperature $\left({ }^{\circ} \mathrm{C}\right)$.

\section{RESULTS}

\section{Relationship of abundances for all Lepidoptera and migrants}

The overall abundance of British Lepidoptera for the period 1864 to 1952 correlates significantly with the number of migrants for the same period $(r=0.379$, resampling $\mathrm{p}=0.001)$.

\section{Relationship of abundance of Lepidoptera with CET, EWP and NAO}

Abundance of British Lepidoptera were significantly positively correlated with Central England temperatures in the current year for each month from May to September and November and significantly negatively correlated with January (Table 2). Numbers were significantly negatively correlated with monthly rainfall in April and May (and with the annual mean) of the current year and August of the previous year (Table 2). Abundance of Lepidoptera decreased significantly with the strength of the winter NAO index $(\mathrm{r}=-0.391$, resampling $\mathrm{p}=0.001)$.

A regression model incorporating mean May-September temperature (Fig. 1) and winter NAO index (Fig. 2) was highly significant $\left(F_{2,86}=18.92, R^{2}=30.6 \%, p<\right.$ 0.001). Forwards selection of monthly CET and EWP added two additional variables; November temperature and May rainfall $\left(\mathrm{F}_{4,84}=13.07, \mathrm{R}^{2}=38.4 \%, \mathrm{p}<0.001\right)$. Residuals from this model passed an Anderson-Darling Normality test $(p=0.866)$. In this final model, coefficients for mean May-September temperature $(p<0.001)$ and for November temperature $(\mathrm{p}=0.016)$ were both positive whilst those for winter NAO index $(p=0.001)$ and May rainfall $(\mathrm{p}=0.019)$ were both negative.

\section{DISCUSSION}

Fluctuations in Beirne's Lepidoptera abundance descriptions matched expectations. Firstly, increased overall abundance in Lepidoptera coincided significantly with increased numbers of migrants and vice versa. Secondly, associations with temperature and rainfall were

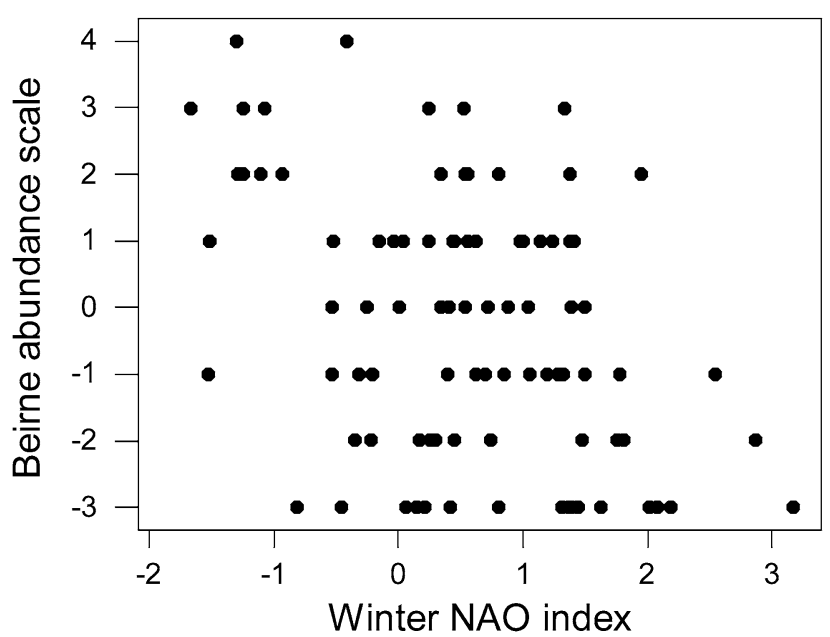

Fig. 2. The relationship between the Beirne abundance scale for British Lepidoptera and the winter (December-March) NAO index.

very similar to those for the British BMS (Pollard, 1988; Roy et al., 2001); higher summer temperatures were linked to higher numbers of Lepidoptera, and increased numbers of depressions (reflected in the strength of the $\mathrm{NAO}$, rainfall and cloud), and higher winter temperatures to lower numbers of Lepidoptera. Considering the nature of the data these relationships are unexpectedly strong. The data measure fluctuations in Lepidoptera as a whole and not individual species. Ecological differences will reduce correlations between Lepidoptera having different habits (e.g. insulation of pupation sites) and between migrant and resident Lepidoptera. Countering this, more or less simultaneous fluctuations in densities of populations of a large number of Lepidoptera species are well recognised by Lepidopterists who regularly coin good years when Lepidoptera are exceptionally common and bad ones when they are abnormally scarce. Captures vary over orders of magnitude reflecting the capacity of Lepidoptera populations to increase rapidly. Even so, the relationships are also bound to be affected by our inability to determine the impact of short term events (e.g. late frosts and short term droughts) or to assess adequately the impact of other variables (e.g. abundances in predators and parasites) (Maelzer, 1970). Substantial historical data discussed by Beirne (1955) affirm the ability of enemies to eradicate Lepidoptera populations (e.g. the great "wasp year" of 1935 and consequences for larval broods of Aglais urticae (small tortoiseshell) and Inachis io (peacock); the massive decline of Nymphalis polychloros (large tortoiseshell) after the severe parasitism of larval broods in 1911). The capacity of insectivorous birds to consume vast numbers of Lepidoptera larvae is well established (e.g. 8,000 larvae by a pair of Parus major (great tit); Witherby et al., 1938; see Krištín \& Patočka, 1997; Mukarami \& Nakanu, 2000).

Beirne's subjective appraisal of his data is confirmed with one exception. He correctly regarded that much of the variation would relate to summer temperatures and precipitation. He also expected that warmer winter tem- 
peratures would be deleterious to Lepidoptera populations, but he was unable to confirm this signal in Lepidoptera abundances though he felt there was an indication that average winters were better for Lepidoptera than warmer or colder ones. The current findings would suggest that warmer conditions in January are deleterious to Lepidoptera population abundances, confirming a long held view in amateur entomology (Beirne, 1955). However, it has been appreciated for an equally long period of time that the impact of winter temperatures depends on species' habits; those underground, in roots or stems would be less affected (Barrett, 1882; see Sparks et al., 2006).

Together, these findings have important implications for projected climate change scenarios (Hill et al., 2002). The link between climate agents and Lepidoptera abundances is supported by independent research and makes good sense (Warren et al., 2001). Higher summer temperatures are expected to benefit Lepidoptera populations in a number of ways, increasing flight, thus mating success and egg laying (Warren et al., 1986; Porter; 1992), leading to increased development rates, more broods and therefore larger numbers through a multiplier effect (Dennis, 1985, 1993; Burke et al., 2005). Increasing development rates reduces mortality rates through shorter exposure time in vulnerable stages with predators and parasites (Pollard, 1979; Leather et al., 1994). Higher winter temperatures are expected to have adverse effects on Lepidoptera, causing disruption to diapause when resources (e.g. host plants in suitable condition) may not be available, promoting disease and more active predation. This was not consistently detected for species (e.g. Pieris brassicae (large white) in the shorter studies of Pollard (1988) or Roy et al. (2001). Rainfall is essential for plant growth and the condition of host plants. However, persistent rainfall and cloud, and heavy rainfall, can be deleterious to Lepidoptera populations. It can depress flight, and therefore activities such as mating and egg laying, cause water logging of host plants and drowning of larvae, trigger disease and infections (Dennis, 1993). Beirne (1955) provides clear instances of the adverse impact of rain on Lepidoptera populations [e.g. Tortrix viridana (green oak roller) and Agrotis segetum (turnip moth)].

These findings generate some expectations with enhanced greenhouse warming in higher latitudes but predictions are not simple (Hulme \& Brown, 1998; Dale, 2005) and may well be countered by loss of habitat (Warren et al., 2001; Hill et al., 2002). Projected scenarios indicate higher temperatures (up to $4^{\circ} \mathrm{C}$ ) during the twenty-first century, both warmer winter and hotter summer conditions throughout Britain, but drier conditions in the south and wetter conditions in the north (Warrick \& Barrow, 1991; IPCC, 2001; Naden \& Watts, 2001). In the south of Britain this suggests that Lepidoptera populations may increase, depending on the negative impact of higher winter temperatures. In the north of Britain the outcome will depend more on the balance between higher temperatures (evaporation) and increased precipitation though it is interesting that 12 butterfly species found to have a positive association between population size and warm summers have experienced major northward expansions in Europe coinciding with warm summers in the late 1990s (Roy et al., 2001) and increases in Lepidoptera populations have occurred elsewhere at altitude in central Europe (Konvička et al., 2004). These indications do not account for the impact of extreme events such as late frosts or droughts which are harmful to populations, the latter indirectly through desiccation of host plants (Pollard, 1988) but again Lepidoptera with populations in northern Britain and at higher altitude may benefit (Hickling et al., 2006). Such projections need also consider indirect effects such as the build up of populations of enemies.

One possible outcome of climatic warming is the increase and persistence (colonisation) of migrant species in Britain (Sparks et al., 2005, 2007). An important observation is that conditions propitious for resident Lepidoptera are generally good for migrants; a warmer climate abroad coinciding with warmer conditions in Britain should permit larger numbers of migrant Lepidoptera to enter Britain, and when here to have greater success in establishing larger populations over summer that will then have greater success in persisting owing also to warmer overwintering conditions. But this is by no means a certain outcome. Although there are indications that resident species can adopt a wider range of biotopes in warmer conditions (Davies et al., 2005) three quarters of 46 British butterflies have apparently declined in the last 30 years; negative responses to habitat change have outweighed positive responses to summer climatic warming (Warren et al., 2001).

The Beirne data clearly demonstrate that there is value in extracting and analysing historical data from the large number of publications across Europe on Lepidoptera species abundances. The only detractor, but an important one, is that abundance has been scored for Lepidoptera as a whole rather than for individual species, which otherwise would have facilitated more detailed analysis and an assessment of changes for distinct components of the Lepidoptera fauna. Nevertheless, it is clear from the text of Beirne's paper that the data extracted by him relate to changes in many species and are not restricted to a few dominant species. They provide further evidence that future climatic changes have consequences for population status and regional species' turnover.

\section{REFERENCES}

BARRETT C.G. 1882: The influence of meteorological conditions on insect life. Entomol. Mon. Mag. 19: 1-8.

BEIRNE B.P. 1955: Natural fluctuations in abundance of British Lepidoptera. Entomol. Gaz. 6: 21-52.

Burke S., Pullin A.S., Wilson R.J. \& Thomas C.D. 2005: Selection for discontinuous life-history traits along a continuous thermal gradient in the butterfly Aricia agestis. Ecol. Entomol. 30: 613-619.

DALE M. 2005: Impact of climate change on UK flooding and future predictions. Proc. Inst. Civil Engin. Water Manag. 158: 135-140. 
Davies Z.G., Wilson R.J., Brereton T.M. \& Thomas C.D. 2005 The re-expansion and improving status of the silver-spotted skipper butterfly (Hesperia comma) in Britain: a metapopulation success story. Biol. Conserv. 124: 189-198.

Dell D., Sparks T.H. \& Dennis R.L.H. 2005: Climate change and the effect of increasing spring temperatures on emergence dates of the butterfly Apatura iris (Lepidoptera: Nymphalidae). Eur. J. Entomol. 102: 161-167.

DenNIS R.L.H. 1985: Voltinism in British Aglais urticae (L.) Lep., Nymphalidae): variation in space and time. Proc. Trans. Br. Entomol. Nat. Hist. Soc. 18: 51-61.

DenNIs R.L.H. 1993: Butterflies and Climate Change. Manchester University Press, Manchester, 302 pp.

Hickling R., Roy D.B., Hill J.K., Fox R. \& Thomas C.D. 2006 : The distributions of a wide range of taxonomic groups are expanding polewards. Global Change Biol. 12: 450-455.

Hill J.K., Thomas C.D., Fox R., Telfer M.G., Willis S.G., Asher J. \& Huntley B. 2002: Responses of butterflies to twentieth century climate warming: implications for future ranges. Proc. R. Soc. Lond. (B) 269: 2163-2171.

Hulme M. \& Brown O. 1998: Portraying climate scenario uncertainties in relation to tolerable regional climate change. Climate Res. 10: 1-14.

Hurrell J.W. 1995: Decadal trends in the North Atlantic Oscillation and relationships to regional temperature and precipitation. Science 269: 676-679.

IPCC 2001: Climate Change 2001: The Scientific Basis. Cambridge University Press, Cambridge, $881 \mathrm{pp}$.

KonvičKa M., Maradová M., Beneš J., Fric Z. \& KepKa P. 2004: Uphill shifts in distribution of butterflies in the Czech Republic: effects of changing climate detected on a regional scale. Global Ecol. Biogeog. 12: 403-410.

KRIŠTín A. \& PATOČKA J. 1997: Birds as predators of Lepidoptera: selected examples. Biologia 52: 319-325.

Leather S.R., Watt A.D., Mills N.J. \& Walters K.A.F. (eds) 1994: Individuals, Populations and Patterns in Ecology. Intercept, Andover, $400 \mathrm{pp}$.

MaELzer D.A. 1970: The regression of $\log N$ as a test of densitydependence: an exercise with computer-constructed densityindependent populations. Ecology 51: 810-820.

Manly B.F.J. 1991: Randomisation and Monte Carlo Methods in Biology. Chapman and Hall, London, 281 pp.

Murakami M. \& NaKanu S. 2000: Species-specific bird functions in a forest-canopy food web. Proc. R. Soc. Lond. (B) 267: $1597-1601$.

NADEN P.S. \& WatTs C.D. 2001: Estimating climate-induced change in soil moisture at the landscape scale: an application to five areas of ecological interest in the UK. Climate Change 49: $411-440$
Parker D.E., Legg T.P. \& Folland C.K. 1992: A new daily central England temperature series, 1772-1991. Int. J. Climatol. 12: 317-342.

Pollard E. 1979: Population ecology and change in range of the white admiral butterfly Ladoga camilla L. in England. Ecol. Entomol. 4: 61-74.

POLLARD E. 1988: Temperature, rainfall and butterfly numbers. J. Appl. Ecol. 25: 819-828.

Pollard E. \& Yates T.J. 1993: Monitoring Butterflies for Ecology and Conservation. Chapman and Hall, London, 274 pp.

Porter K. 1992: Eggs and egg-laying. In Dennis R.L.H: The Ecology of Butterflies in Britain. Oxford University Press, Oxford, pp. 46-72.

Roy D.B., Rothery P., Moss D., Pollard E. \& Thomas J.A. 2001: Butterfly numbers and weather: predicting historical trends in abundance and the future effects of climate change. J. Anim. Ecol. 70: 201-217.

Sparks T.H., Roy D.B. \& DenNis R.L.H. 2005: The influence of temperature on migration of Lepidoptera into Britain. Global Change Biol. 11: 507-514.

Sparks T.H., Huber K. \& DenNis R.L.H. 2006: Complex phenological responses to climate warming trends? Lessons from history. Eur. J. Entomol. 103: 379-386.

Sparks T.H., Dennis R.L.H., Croxton P.J. \& Cade M. 2007: Increased migration of Lepidoptera linked to climate change. Eur. J. Entomol. 104: 139-143.

Warren M.S., Pollard E. \& BibBy T.J. 1986: Annual and longterm changes in a population of the wood white butterfly Leptidea sinapis. J. Anim. Ecol. 55: 707-720.

Warren M.S., Hill J.K., Thomas J.A., Asher J., Fox R., Huntley B., Roy D.B., Telfer M.G., Jeffcoate S., Harding P., Jeffcoate G., Willis S.G., Greatorex-Davies J.N., Moss D. \& Thomas C.D. 2001: Rapid responses of British butterflies to opposing forces of climate and habitat change. Nature 414: 65-69.

WARRICK R.A. \& BARROW E.M. 1991: Climate change scenarios for the UK. Trans. Inst. Br. Geogr. 16: 387-399.

Wigley T.M.L., Lough J.M. \& Jones P.D. 1984: Spatial patterns of precipitation in England and Wales and a revised homogeneous England and Wales precipitation series. J. Climatol. 4: $1-25$.

Williams C.B. 1965: Insect Migration. Collins, London, 237 pp. Witherby H.F., Jourdain F.R.C., Ticehurst N.F. \& TucKer B.W. 1938: The Handbook of British Birds. H.F. and G. Witherby, London, $326 \mathrm{pp}$.

Received January 25, 2007; revised and accepted June 15, 2007 